\title{
Pedagogiek en recht: schijnbare tegenstelling?
}

\author{
M.E. Kalverboer *
}

\section{Inleiding}

In deze inleiding laat ik de eerste resultaten zien van het onderzoeksproject 'Belang van het kind in het jeugdstrafrecht'. Het onderzoeksproject wordt sinds 2008 uitgevoerd door de afdeling Orthopedagogiek van de Rijksuniversiteit Groningen. Het omvat twee samenhangende thema's: de afdoening van delicten die gepleegd worden door jongeren die onder het jeugdstraf(proces)recht vallen en de wijze waarop deze jongeren voorbereid worden op het juridisch proces en de rechtszitting. Beide thema's worden bestudeerd in relatie tot de specifieke bepalingen van het Verdrag voor de Rechten van het Kind (VRK of Kinderrechtenverdrag) die voor het jeugdstraf(proces)-recht belangrijk zijn.

Het project is een vervolg op een eerdere studie in het vreemdelingenrecht. ${ }^{1}$ Deze studie heeft onder andere de vragenlijst 'Belang van het kindVreemdelingenrecht' opgeleverd; een vragenlijst voor juridische besluitvorming rond verblijfsaanvragen in vreemdelingenprocedures. Met behulp van de vragenlijst kan worden vastgesteld wat de kwaliteit van de opvoe-

\footnotetext{
Margrite Kalverboer is als universitair docent werkzaam op het gebied van de orthopedagogiek en kinderrechten bij de afdeling Orthopedagogiek van de Faculteit Gedrags en Maatschappijwetenschappen van de Rijksuniversiteit Groningen, ze is orthopedagoog en jurist.

1 M.E. Kalverboer \& A.E. Zijlstra, Het belang van het kind in het Vreemdelingenrecht; kinderen uit asielzoekersgezinnen, Ontwikkeling, perspectief en juridische positie, Groningen; Rijksuniversiteit Groningen, 2008. M.E. Kalverboer \& A.E. Zijlstra, Het belang van het kind in het Nederlands recht: voorwaarden voor ontwikkeling vanuit een pedagogisch perspectief, Amsterdam: SWP, 2006. M.E. Kalverboer \& A.E. Zijlstra, Asielzoekerskinderen en het recht op ontwikkeling, Amsterdam: SWP, 2006.
} 
dingsomgeving is waarin het kind opgroeit en of terugkeer naar het thuisland tot ontwikkelingsrisico's bij het kind leidt. Tevens kan met de lijst worden aangegeven welke bepalingen uit het Kinderrechtenverdrag geschonden worden wanneer de kwaliteit van de opvoedingsomgeving naar verwachting onvoldoende is. Op verzoek van Stichting Kinderpostzegels Nederland wordt de vragenlijst 'Belang van het kind-Vreemdelingenrecht' uitgewerkt voor juridische besluitvormingsprocedures in het jeugdstraf(proces)recht wanneer de afweging moet worden gemaakt of de afdoening van het delict door de kinderrechter het ontwikkelingsbelang van het kind dient.

Het Verdrag voor de Rechten van het Kind (VRK)

Het Verdrag voor de Rechten van het Kind is in 1995 in Nederland in werking getreden. Het verdrag is van toepassing op de situatie van kinderen in alle rechtsgebieden waarmee ze te maken kunnen krijgen en moet daarom als leidraad worden beschouwd voor de bejegening van kinderen in het strafproces. Twee artikelen uit dit verdrag zijn specifiek gericht op de jeugdige verdachten en het straf(proces)recht. Het gaat om de artikelen 37 en 40 VRK. Artikel 37 VRK geeft kinderen het recht beschermd te worden tegen marteling, andere wrede, onmenselijke of denigrerende behandeling of straf, doodstraf, levenslange vrijheidsberoving zonder de mogelijkheid van vervroegde invrijheidstelling en onrechtmatige of arbitraire vrijheidsberoving. Iedere vorm van arrestatie, detentie of gevangenschap van een kind moet in overeenstemming zijn met de wet, een laatste of uiterste middel zijn en voor de kortst mogelijke tijd ten uitvoer worden gelegd. Artikel 40 VRK gaat over de rechten van kinderen die worden verdacht, vervolgd of van wie is bewezen dat zij de strafrechtelijke normen hebben overtreden. Dit artikel is sterk verbonden met artikel 37 VRK. Volgens het eerste lid van artikel 40 VRK hebben kinderen recht op een behandeling die geen afbreuk doet en rekening houdt met hun gevoel van waardigheid en eigenwaarde, met respect voor de mensenrechten van het kind, de leeftijd van het kind en de wenselijkheid van het bevorderen van re-integratie. Voor de verwezenlijking van dit recht zijn in artikel 40 lid twee, drie en vier VRK een aantal specifieke verplichtingen van de Staten aangegeven. Art. 40 lid drie en vier VRK geven beide de norm weer dat Staten moeten proberen kinderen zoveel mogelijk buiten de straf- 
rechtelijke procedures te houden en naar andere mogelijkheden te zoeken. Dit wordt diversion genoemd. ${ }^{2}$

Naast de specifiek op het jeugdstrafrecht gerichte artikelen uit het Kinderrechtenverdrag, moet implementatie van een systeem van jeugdstrafrechtpleging plaatsvinden via de algemene beginselen van het VRK. Dit impliceert dat de vier kernartikelen uit het verdrag: artikel 2 VRK (het nondiscriminatie-artikel), artikel 3 lid 2 VRK (het belang van het kind is eerste overweging), artikel 6 lid 2 VRK (het kind heeft het inherente recht op ontwikkeling) en artikel 12 VRK (het kind dient gehoord te worden), hun doorwerking hebben. Echter ook andere artikelen uit het Kinderrechtenverdrag die niet specifiek van toepassing zijn op het jeugdstrafrecht kunnen doorwerken in het jeugdstrafrecht. Deze doorwerking betreft de procesrechtelijke aspecten als ook de toepassing van het materiële recht en de wijze van de ten uitvoerlegging van straffen en maatregelen.

\section{De strafrechtelijke procedure}

Voordat de straf of maatregel wordt uitgesproken krijgen kinderen die verdacht zijn van het plegen van een delict te maken met verschillende procedurele aspecten van het jeugdstrafrecht. Kinderen kunnen worden aangehouden, verhoord, in bewaring of in verzekering gesteld en in voorlopige hechtenis worden genomen. Ze maken politieverhoren en soms meerdere rechtszittingen mee. De strafrechtelijke maatregelen Plaatsing in een inrichting voor jeugdigen (PIJ) en de Gedragsbeïnvloedende Maatregel kunnen worden opgelegd mits deze het ontwikkelingsbelang van het kind dienen. Als kinderen en hun ouders goed voorbereid worden op de procedure en de zitting, zal de rechter een beter beeld van het kind, diens ouders en de kwaliteit van de opvoedingsituatie krijgen. Dit bevordert een zorgvuldige afweging waarbij het ontwikkelingsbelang van het kind wordt meegewogen bij de afdoening van het delict.

Geluiden uit de praktijk duiden erop dat kinderen niet altijd goed voorbereid zijn op de zitting bij de kinderrechter waardoor ze zich op een wijze aan de kinderrechter, de officier van justitie en de overige bij de zitting aanwezigen presenteren die in hun nadeel werkt. Tevens bestaat de indruk dat de wijze

2 Stan Meuwese, Mirjam Blaak, Marjorie Kaandorp (red.) Handboek internationaal jeugdrecht, p. 504. Nijmegen: Ars Aequi Libri, 2005. 
waarop de ouders zich tijdens de zitting opstellen mede van invloed is op de afdoening van het delict. Als ouders het delict van het kind tijdens de zitting bagatelliseren of als zij zich op andere wijze niet passend gedragen, is de kans op een zwaardere afdoening groter dan wanneer ouders het kind een gepaste correctie hebben gegeven en zich coöperatief opstellen. ${ }^{3}$ Over hoe de officier van justitie tot zijn eis, hoe de kinderrechter tot zijn uitspraak komt, hoe zittingen verlopen en wat de beste houding tijdens het proces is, krijgen kinderen en ouders niet altijd voldoende informatie. In het bijzonder kinderen die weinig weten over de procedure en wat hen te wachten staat, kunnen hierdoor minder goed gebruik maken van de hen toegekende (kinder)rechten dan kinderen die wel goed geïnformeerd, op de hoogte en voorbereid zijn. Verder is het kinderen en ouders lang niet altijd duidelijk welke informatie relevant is voor de het door de kinderrechter te nemen besluit.

\section{Vraagstelling}

In het onderzoek combineren we twee thema's. We verwachten dat met behulp van de vragenlijst 'Belang van het kind en voorwaarden voor ontwikkeling' een inschatting kan worden gemaakt van de kwaliteit van de opvoedingsomgeving van het kind in verschillende alternatieve situaties en bij verschillende juridische besluiten. Hoe is deze kwaliteit bijvoorbeeld als het kind in een justitiële jeugdinrichting wordt geplaatst, in een jeugdzorgplus-inrichting of bij verblijf in het thuismilieu? De lijst kan gebruikt worden ter ondersteuning van het besluit waarbij aandacht besteed wordt aan de vraag bij welke afdoening het ontwikkelingsbelang van het kind het beste wordt gediend.

Verder verwachten we dat als kinderen en ouders goed voorbereid worden op de juridische procedure en de rechtszitting, hun kinderrechten beter gewaarborgd worden en de kinderrechter een beter beeld krijgt van het kind en zijn ouders. Dit zal de afweging voor de keuze van de afdoening vergemakkelijken. Een en ander heeft geleid tot de volgende vraagstellingen die in het onderzoek nader worden uitgewerkt: 
'Hoe kan de vragenlijst 'Belang van het kind en voorwaarden voor ontwikkeling' toegepast worden ter ondersteuning van de besluitvorming in het jeugdstrafrecht om vast te stellen welke afdoening van het delict passend is in het licht van de toepasselijke wet- en regelgeving en het Kinderrechtenverdrag?'

en

'Hoe moeten kinderen worden voorbereid op de rechtsprocedure en -zitting zodat rekening gehouden wordt met hun ontwikkelingsniveau en hun rechten gewaarborgd worden?'.

\section{De uitvoering van het onderzoek}

Aan de vragenlijst 'Belang van het Kind en voorwaarden voor ontwikkeling in strafzaken' ligt het Best Interest of the Child-model (BIC-model) ten grondslag. Het model is gebaseerd op pedagogisch en psychologisch onderzoek omtrent ontwikkelingsvoorwaarden in relatie tot ontwikkelingsrisico's. Tevens is de lijst gebaseerd op de kernartikelen uit het Verdrag voor de rechten van het kind. Het BIC-model geeft het begrip 'het belang van het kind' (art. 3 VRK) een inhoudelijke invulling. Het belang van het kind wordt geduid als het belang van zijn ontwikkeling (art. 6 VRK). Ontwikkeling van kinderen wordt bezien vanuit de visie dat omgevings- en kindfactoren de uiteindelijke ontwikkelingsuitkomsten beïnvloeden. Uit internationale literatuurstudie blijkt dat veertien omgevingsfactoren gezamenlijk bijdragen aan optimale ontwikkelingskansen voor kinderen. Afwezigheid hiervan leidt tot ontwikkelingsproblemen bij kinderen en schending van het Kinderrechtenverdrag. ${ }^{4}$ In welke mate kinderen hiervan schade ondervinden hangt samen met de kwetsbaarheid van het kind. Caprara en Rutter hebben onderzocht wat de kwetsbaarheid van een kind bepaalt. Zij noemen de volgende factoren: het kind is kwetsbaar in aanleg, het heeft eerdere stressvolle ervaringen meegemaakt, het is de enige in het gezin die aversieve ervaringen meemaakt, het gezin heeft een uitzonderingspositie in de samenleving, er is een stapeling van risico-ervaringen, risico's hebben plaats in een voor de

4 M.E. Kalverboer \& A.E. Zijlstra, Het belang van het kind in het Nederlands recht: voorwaarden voor ontwikkeling vanuit een pedagogisch perspectief, Amsterdam: SWP, 2006. 
ontwikkeling van het kind vatbare periode en het kind beschikt over slechte coping strategieën. ${ }^{5}$ We noemen het model in dit onderzoek BIC-Straf (BIC-S).

De vragenlijst (BIC-S) bevat dezelfde lijst van 14 noodzakelijke ontwikkelingsvoorwaarden waarover 24 vragen zijn geformuleerd. De ontwikkelingsvoorwaarden bepalen tezamen de kwaliteit van de opvoedingssituatie van het kind. Het gaat om voorwaarden die in het gezin (opvoedingssysteem) van het kind langdurig beschikbaar moeten zijn en om voorwaarden die in de samenleving voor het kind langdurig beschikbaar moeten zijn. In figuur 1 vindt $\mathrm{u}$ het BIC-model.

\section{BIC-model \\ Gezin: actuele situatie}

Fysiek welzijn

1. Adequate verzorging

Adequate verzorging is de zorg voor gezondheid en fysiek welbevinden (bijvoorbeeld het bieden van ruimte, verwarming, kleding, persoonlijk eigendom, voeding, inkomen) passend bij het kind. Daarnaast ervaren de ouders geen zorgen met betrekking tot deze conditie.

2. Een veilige fysieke directe omgeving

Een veilige fysieke directe omgeving biedt lichamelijke bescherming aan het kind. Dat betekent afwezigheid van gevaar in de woning en omgeving, afwezigheid van bedreigende toxische invloeden, afwezigheid van mishandeling en afwezigheid van geweld in de omgeving van het kind.

\section{Opvoeding}

3. Affectief klimaat

Geborgenheid, steun en begrip van de ouder, passend bij het kind en tot uiting komend in de relatie die het kind met zijn ouder heeft.

5 G.V. Caprara en M. Rutter. Individual Development and Social Change. In M. Rutter and M. Smith (eds). Psychological disorders in Young people Time, Trends and Their Causes. Chichester: John Wiley and Sons Lyd. 1995, p.35-66. 
4. Ondersteunende flexibele opvoedingsstructuur

- Voldoende regelmaat in het leven van alledag.

- Aanmoediging, stimulering, geven van instructie en het stellen van realistische eisen.

- Het stellen van grenzen, het geven van regels, het geven van inzicht in en argumenten voor de gestelde grenzen en regels.

- Het uitoefenen van controle op het gedrag van het kind.

- Het voldoende ruimte laten aan het kind voor eigen wensen en vrijheid voor eigen initiatief en experimenteren, evenals de vrijheid om over de structuur te (leren) onderhandelen.

- Het kind krijgt niet meer verantwoordelijkheid dan hij aankan en ervaart zo binnen die begrenzing de gevolgen van zijn gedrag en leert zo de gevolgen in te schatten en zijn gedrag af te wegen.

5. Adequaat voorbeeld gedrag ouder

Het kind neemt gedrag, optreden, waarden en normen van zijn ouders over die nu en later van belang zijn.

6. Interesse

Het tonen van belangstelling voor het kind en zijn leefwereld door de ouder.

\section{Gezin: toekomst en verleden}

\section{Continuïteit in opvoeding en verzorging, toekomstperspectief}

Een ouder verzorgt het kind en voedt het zodanig op dat er hechting optreedt. Het basisvertrouwen dat ontstaat wordt in stand gehouden door de beschikbaarheid van de ouder. Het kind ervaart een toekomstperspectief.

\section{Samenleving: actuele situatie}

8. Een veilige fysieke wijdere omgeving

Een veilige fysieke wijdere omgeving biedt lichamelijk bescherming aan het kind. De buurt waarin het kind opgroeit, is veilig evenals de samenleving. Criminaliteit, oorlogen, natuurrampen, besmettelijke ziekten zijn afwezig.

9. Respect

De behoeften, wensen, gevoelens en verlangens van het kind worden serieus genomen door de omgeving van het kind. 
10. Sociaal netwerk

Het kind (gezin) heeft diverse steunbronnen in zijn omgeving waarop hij een beroep kan doen.

11. Educatie

Het kind krijgt scholing en opleiding en de gelegenheid tot het ontplooien van talenten (bijvoorbeeld sport of muziek).

12. Omgang met leeftijdsgenoten

Het kind heeft omgang met andere kinderen in gevarieerde situaties passend bij de belevingswereld en het ontwikkelingsniveau van het kind.

13. Adequaat voorbeeldgedrag samenleving

Het kind komt in contact met andere kinderen en volwassenen van wie hij gedrag, optreden, waarden en normen kan overnemen die voor hem nu en later van belang zijn.

\section{Samenleving: toekomst en verleden}

\section{Stabiliteit in levensomstandigheden, toekomstperspectief}

De omgeving verandert niet onvoorzien en plotseling. Optredende veranderingen komen aangekondigd en zijn inzichtelijk voor het kind. Identificatiefiguren en steunbronnen blijven bestaan, evenals de mogelijkheid tot het aangaan van relaties door eenheid van taal. De samenleving biedt het kind een toekomstperspectief.

\section{Figuur 1 BIC-model}

Wanneer een ontwikkelingsvoorwaarde uit het model langdurig niet van voldoende kwaliteit is, betekent dit een risico voor de ontwikkeling van het kind. Dit kan betekenen dat het kind gedragsproblemen of delictgedrag ontwikkelt. In het bijzonder kwetsbare kinderen kunnen in hun ontwikkeling geschaad worden wanneer een conditie langdurig van onvoldoende kwaliteit is. Besluitvorming op basis van de vragenlijst 'Belang van het kind- en voorwaarden voor ontwikkeling in strafzaken' en het VRK heeft als uitgangspunt dat bij alle besluiten die het kind raken, het belang van het kind eerste overweging dient te zijn (art. 3 lid 1 VRK) en dat het kind recht heeft op een continue ontwikkeling (art. 6 lid 2 VRK). Met behulp van de vragenlijst wordt vastgesteld in welke alternatieve situatie het ontwikkelingsbelang van het kind het best wordt gediend. Het kind dient hierbij gehoord te worden (art. 12 VRK) en opsluiten wordt slechts als laatste middel gehanteerd 
(art. 40 sub c VRK). De lijst kan in het jeugdstrafrecht worden gelieerd aan de artikelen $77 \mathrm{~s} \mathrm{Sr}$ (plaatsing in een inrichting voor jeugdigen) en $77 \mathrm{w} \mathrm{Sr}$ (gedragsbeïnvloedende maatregel). Beide maatregelen mogen slechts worden opgelegd als zij in het belang zijn van een zo gunstig mogelijke ontwikkeling van het kind. ${ }^{6}$

\section{Eerste resultaten met de vragenlijst}

Ter validering van de BIC-S is de vragenlijst afgenomen bij jongeren die in de periode 2008-2009 op civielrechtelijke of strafrechtelijke titel in de justitiële jeugdinrichting Het Poortje ${ }^{7}$ verblijven. De dataverzameling vond plaats in de context van het lopend onderzoek naar doelgroepkenmerken van jongeren die in Het Poortje verblijven en de effecten van interventies op hun gedrag. Door onderzoekers van de afdeling Orthopedagogiek is de BIC-S ingevuld, vlak na binnenkomst van de jongeren in Het Poortje. Met de lijst is de kwaliteit van de opvoedingsomgeving waar de jongeren leefden direct vooraf aan plaatsing in Het Poortje vastgesteld (zie tabel 1).

Hoewel het hier om eerste resultaten gaat, laat zich een trend zien dat er aanzienlijke verschillen zijn tussen de opvoedingsomgeving van de civielrechtelijk en strafrechtelijk geplaatste jongeren direct voorafgaand aan de plaatsing. Zo is de kwaliteit van een aantal opvoedingscondities binnen het opvoedingssysteem, het gezin, bij de civielrechtelijk geplaatste jongeren aanzienlijk lager dan bij de strafrechtelijk geplaatste jongeren. Voor wat betreft de kwaliteit van de condities in de samenleving ontstaat de indruk dat bij de civielrechtelijk geplaatste kinderen beduidend minder vaak sprake is van continuïteit in levensomstandigheden dan bij strafrechtelijk geplaatste kinderen. Of deze verschillen significant zijn, moet onderzoek bij een grotere steekproef uitwijzen.

6 Art. 77s lid 1 sub c Sr: de maatregel is in het belang van een zo gunstig mogelijke verdere ontwikkeling van de verdachte.

Art. 77w lid 1 sub b: de maatregel is in het belang van een zo gunstig mogelijke verdere ontwikkeling van de verdachte.

7 Het Poortje is de jeugdzorgplusinstelling Wilster te Groningen en de justitiële jeugdinrichting Juvaid te Veenhuizen. 


\begin{tabular}{|c|c|c|}
\hline Kwaliteit per conditie & Voldoende/Goed & \\
\hline Gezin/ & Civiel & Straf \\
\hline Adequate verzorging & 78.5 & 75.1 \\
\hline Veilige fysieke omgeving & 64.8 & 70.8 \\
\hline Affectief klimaat & 26.1 & 49.9 \\
\hline Ondersteunende flexibele opvoedingsstructuur & 7.1 & 16.6 \\
\hline Adequaat voorbeeldgedrag ouders/verzorgers & 23.8 & 41.6 \\
\hline Interesse in het kind & 30.9 & 41.6 \\
\hline Continuïteit in opvoeding en verzorging & 2.4 & 16.6 \\
\hline \multicolumn{3}{|l|}{ Samenleving } \\
\hline Veilige fysieke wijdere omgeving & 19 & 12.5 \\
\hline Respect & 50 & 45.8 \\
\hline Sociaal netwerk & 33.3 & 24.9 \\
\hline Educatie & 14.3 & 20.8 \\
\hline Omgang met leeftijdsgenoten & 7.2 & 4.1 \\
\hline Adequaat voorbeeldgedrag samenleving & 9.6 & 20.8 \\
\hline Continuïteit in levensomstandigheden & 0 & 20.8 \\
\hline
\end{tabular}

Tabel 1: De kwaliteit van de opvoedingsomgeving in de thuissituatie vooraf aan de plaatsing van jongeren in het Poortje in percentages.

Totaal $\mathrm{N}=66$; Civiel rechterlijk geplaatst $\mathrm{N}=42$ (63.6\%); Strafrechtelijk geplaatst $\mathrm{N}=24(36.3 \%)$

\section{Eerste resultaten rond de voorbereiding van jongeren}

Het uitgangspunt bij de ontwikkeling van een voorbereidingsprogramma is dat wanneer kinderen een beter inzicht krijgen in hun eigen gedrag, de consequenties van hun handelen en het effect van hun gedrag op anderen een begin van een veranderingsproces op gang gebracht wordt. Een ander uitgangspunt is dat niet alle kinderen op een gelijke manier gebruik maken van hun rechten. Verder bestaat de verwachting dat als kinderen zich slecht op hun gemak voelen, het moeilijk is om een goed beeld van ze te krijgen. 
Het onderzoek bestaat uit een literatuurstudie naar de voorbereiding van jongeren op de zitting. In internationale literatuur is gezocht naar hoe childfriendly courts eruit moeten zien. Tevens is een praktijkonderzoek uitgevoerd in samenwerking met Het Poortje. In de voorstudie is aan 19 jongeren gevraagd naar hun ervaringen met de zitting en de voorbereiding op de zitting. Al deze jongeren waren medio 2008 in Het Poortje geplaatst. Uit de betreffende studie blijkt dat jongeren te weinig begrijpen van wat er tijdens de zitting gebeurt en dat ze de consequenties van hun gedrag tijdens de zitting onvoldoende kunnen overzien. Verder blijkt dat ze hun rechten onvoldoende kennen. Ook blijkt dat ouders hun rol/positie tijdens de strafrechtelijke procedure onvoldoende kennen. ${ }^{8}$ In tabel 2 is weergegeven hoe de ondervraagde jongeren die een zitting hebben meegemaakt deze hebben ervaren.

\section{Ervaringen van jongeren}

Jongeren zijn slecht voorbereid op de (1e) zitting die ze meemaken; ze leren uit ervaring.

Jongeren hebben het idee dat de kinderrechter geen goed beeld van hen heeft gekregen.

Jongeren kennen hun rechten niet.

Jongeren begrijpen niet wat er wordt gezegd; er worden te veel moeilijke woorden gebruikt.

Jongeren voelen zich slecht op hun gemak waardoor ze blokkeren en de rechter en de officier van justitie volgens hen geen goed beeld van ze heeft gekregen.

Instellingen en advocaten gaan ervan uit dat ze kinderen goed voorbereiden.

Tabel 2 Ervaringen van civiel- en strafrechtelijk geplaatste jongeren $\mathrm{N}=19$

8 B. Dijkstra en M. Fieten, Hoe zit het in het jeugdstrafrecht; onderzoek naar de voorbereiding en kindvriendelijkheid van een zitting, Groningen: Rijksuniversiteit Groningen, 2008. 


\section{Voorlopige conclusies ten aanzien van beide thema's}

De eerste bevindingen bij de afname van de BIC-S bij de steekproef van kinderen die in Het Poortje verblijven, duiden erop dat de kwaliteit van de opvoedingsomgeving waarin ze opgroeiden vooraf aan hun plaatsing in Het Poortje vaak onvoldoende is. De situatie binnen het gezin van kinderen die civielrechtelijk geplaatst zijn, steekt ongunstig af bij die van de strafrechtelijk geplaatste kinderen. Over hoe kinderen voorbereid worden op de procedure is in dit stadium van onderzoek nog niet veel te zeggen. De eerste indruk is dat dit niet altijd adequaat gebeurt en dat dus de kans bestaat dat de kinderrechter en de officier tijdens de zitting geen goed beeld van het kind krijgen.

\section{Vervolgstudie}

Ten aanzien van beide thema's die besproken zijn, vindt vervolgstudie plaats. Ten behoeve van het thema rond de ontwikkeling en de toepassingsmogelijkheden van de vragenlijst vindt validiteitonderzoek plaats. Hiervoor is bij iedere jongere voor wie een BIC-S is ingevuld tevens een vragenlijst afgenomen die informatie geeft over de gedragsproblemen van de jongere en over zijn eigen perceptie hiervan. Het gaat om de VSPS (Vragenlijst Sociaal Pedagogische Situatie) en een YSR (Youth Self Report). In het vervolg van de studie zal worden gekeken of de samenhang die we verwachten tussen de kwaliteit van de opvoedingsomgeving en de gedragsproblemen van de kinderen ook werkelijk bij de onderzochte groep gevonden wordt. Verder zal worden onderzocht hoe met behulp van de vragenlijst een ondersteunend advies kan worden geformuleerd voor de kinderrechter omtrent bijvoorbeeld PIJ-verlenging, het opleggen van een Gedragsbeïnvloedende maatregel of een andere afdoening. Hiervoor wordt samengewerkt met jeugdadvocaten. Tot slot wordt een kindversie van de vragenlijst gemaakt waarin het kind zelf zijn ontwikkelingsbelang naar voren brengt. Jongeren die in Het Poortje verblijven worden bij de ontwikkeling van deze kindversie betrokken.

Ook ten aanzien van het thema 'voorbereiding op de procedure en de zitting' vindt vervolgonderzoek plaats. In dit onderzoek worden kinderen die te maken hebben met een strafrechtelijke vervolging en hun ouders gevraagd naar hun ervaringen. Er wordt samengewerkt met jeugdadvocaten om zo het hele proces te volgen. Tevens vinden er observaties plaats tijdens jeugdzit- 
tingen. Het gaat hierbij om strafrechtelijke zittingen. Verder zal in samenwerking met Het Poortje naar aanleiding van de onderzoeksbevindingen een methodiek ontwikkeld worden om met jongeren te 'oefenen' voor de zitting. Met jongeren uit Het Poortje zullen zo waarheidsgetrouw mogelijk zittingen worden nagespeeld waarbij de jongeren de rol van verdachte, rechter, officier of rapporteur pro justitia krijgen toegewezen. Het doel hiervan is hun inzicht in het proces en hun eigen gedrag te vergroten en hen zodanig voor te bereiden op een eventuele vervolgzitting dat de bij de zitting aanwezigen een goed beeld van de jongere en diens gedrag krijgen.

Terugkomend op de titel van dit betoog: is er sprake van een tegenstelling tussen pedagogiek en recht? In ons onderzoek ervaren we een tegenstelling, echter door de dialoog te zoeken lijkt deze tegenstelling overbrugbaar. 